\title{
POTENCIAL DE UM SISTEMA DE MATEMÁTICA DINÂMICA NO ESTUDO DE TRANSFORMAÇÕES LINEARES
}

\section{Potential of A Dynamic Mathematics System in the Study of Linear Transformations}

\author{
Carmen Vieira Mathias*
}

José Carlos Pinto Leivas**

\begin{abstract}
Resumo: Neste artigo, investiga-se como a visualização pode ser uma ferramenta de aprendizagem epistêmica ${ }^{1}$ ao utilizar o potencial didático de um Sistema de Matemática Dinâmica (SMD) para revisitar conceitos sobre transformações lineares bidimensionais. Para isso, foca-se em algumas funções do SMD, em particular nos livros digitais (GeoGebra Books), nos grupos (GeoGebra Groups) e na percepção visual dos estudantes. A pesquisa, classificada quanto aos procedimentos técnicos como um estudo de caso e de abordagem qualitativa, foi realizada com cinco alunos de um curso de pós-graduação em uma universidade privada. Concluiu-se que as atividades realizadas não tiveram o alcance esperado para a maioria dos participantes, visto que estes fugiram do objetivo inicial. Porém, para esses sujeitos, elas serviram como uma revisão de conceitos sobre o assunto em questão. Observou-se que o SMD auxiliou a explorar as percepções visuais acerca do tópico escolhido, especialmente para um dos participantes.
\end{abstract}

Palavras-chave: Transformações Lineares; Visualização; Geogebra Book; GeoGebra Groups.

Abstract: In this article, we investigate how visualization can be an epistemic learning tool using the didactic potential of a Dynamic Mathematics System (DMS) to revisit concepts of two-dimensional linear transformations. To do this, it focuses on some DMS functions, in particular digital books (GeoGebra Books); GeoGebra Groups and students' visual perception. The research, classified concerning the technical procedures as a case study and a qualitative approach, was carried out with five students of a postgraduate course at a private university. It was concluded that the activities performed did not reach the expected range for most participants, as they fled from the initial objective. However, for these participants, they served as a review of concepts. It was observed that the DMS helped to explore the visual perceptions about the chosen topic, especially for one of the participants.

Keywords: Linear transformations; Visualization; Geogebra Book; GeoGebra Groups.

\footnotetext{
* Doutora em Matemática. Professora Associada do Departamento de Matemática da UFSM. carmen@ufsm.br. Orcid: https://orcid.org/0000-0001-5667-159X

** Doutor em Educação. Programa de Pós-Graduação em Ensino de Ciências e Matemática, UFN. leivasjc@ufn.edu.br. Orcid: https://orcid.org/0000-0001-6876-1461

${ }^{1}$ [...] envolve uma mudança da epistemologia ou modo operatório de conhecer e pensar, que molda a percepção das pessoas do mundo e a interação delas com ele (STERLING ,2011).
} 


\section{Introdução}

O conceito de transformação linear é um dos mais abstratos estudados em Álgebra Linear. Também pode ser considerado um daqueles com os quais os alunos experimentam dificuldades consideráveis (FURTADO, 2010; CARDOSO, 2014). Conforme Furtado (2010), algumas dessas dificuldades podem estar relacionadas às concepções de funções construídas anteriormente, uma vez que transformação é um tipo especial de função definida entre espaços vetoriais.

Ao tratar dos processos de ensino e aprendizagem em Álgebra Linear, Silva, Alves e Almeida (2018) discorrem sobre a forma tradicional como a mesma é encontrada no cenário brasileiro e focam na formação de professores de Matemática e que "não se limite a ensinar apenas o conteúdo, incorporando também aspectos de sua formação didático-pedagógica, por exemplo, colocar os estudantes em situações metodológicas diferentes da tradicional" (p. 99).

Ainda sobre as dificuldades encontradas pelos alunos, Kripka (2018) observa que alguns estudantes possuem problemas para realizar a conversão entre registros, especialmente do registro gráfico para o algébrico. Nesse caso, é sugerido, pela autora, utilizar tecnologias digitais, para favorecer os processos de ensino e de aprendizagem em Álgebra Linear, facilitando a mediação pedagógica, a compreensão e a construção de conceitos matemáticos.

Outros trabalhos envolvendo aplicabilidade de conceitos desenvolvidos na disciplina de Álgebra Linear nos cursos de Engenharia (PARMEGIANI, 2011; ROSA et al., 2009 e BRONDINO e BRONDINO, 2012) apresentam exemplos utilizando softwares como o Matlab, Winplot ou planilhas eletrônicas. Segundo esses autores, tais softwares poderão servir como suporte ao ensino de conceitos relacionados a transformações lineares, sugerindo a visualização de registros distintos para auxiliar no entendimento desse tópico.

Observa-se que conceitos atrelados a transformações lineares, principalmente sobre a visualização da representação geométrica destas, têm aplicações em computação gráfica e robótica, por exemplo. Geralmente, tais aplicações focam em objetos e seus respectivos movimentos, como evidenciam Anton e Rorres (2012) ao explorarem as transformações lineares na visualização de um objeto tridimensional em um espaço bidimensional.

Sobre a função da visualização nas transformações, pioneiros a abordarem o tema e que são referências nas pesquisas, Eisenberg e Dreyfus (1994) apresentam a diferença entre uma visualização estática, a qual consiste em "mover um gráfico de um estado inicial para um final, ou seja, o gráfico ter movimentado e mudado durante uma transformação" (p. 58) e uma visão dinâmica, que consiste em visualizá-la como "um mapeamento que está movendo todos os pontos do plano para um novo local" (p. 58). Na primeira abordagem, a ênfase está nos dois estados estáticos, enquanto que, na última, o foco está no movimento dinâmico, que começa com o estado inicial e termina no final.

Nesse contexto, Presmeg (2014) adverte que as pesquisas apresentam uma lacuna no que diz respeito ao papel da visualização no contexto de salas de aula de Matemática, e como a sua influência pode promover a aprendizagem de tópicos específicos dessa disciplina.

A motivação para a presente investigação possui como suporte Presmeg (2014), ao procurar investigar o papel epistemológico da visualização, ou seja, uma teoria da cognição (epistemologia) relativa à visualização. Pretende-se, durante a pesquisa, levar em consideração as diferenças individuais na preferência pelo pensamento visual. 
Segundo Presmeg (2014),

para a maioria das pessoas, a tarefa em si, as instruções e os fatores socioculturais influenciam se eles tentam uma solução visual quando há a escolha. Mas (...) há "visualizadores" que sempre tentam fazer uma figura se ela não for dada, e também “não visualizadores” que não sentem essa necessidade. (PRESMEG, 2014, p.152, tradução nossa).

Assim, acredita-se que é preciso investigar o quanto a visualização, aliada às ferramentas tecnológicas, será eficaz no processo de aprender e ensinar transformações lineares pelas diferenças individuais na necessidade de visualizar certos objetos e pelos tipos de visualização que os indivíduos criam espontaneamente.

Neste estudo, procura-se explorar essas questões examinando concepções de um grupo de pós-graduandos sobre o tema escolhido, explorando o potencial da visualização nas soluções de tarefas que envolvem representações geométricas dinâmicas de transformações lineares. Essas atividades foram disponibilizadas em um Sistema de Matemática Dinâmica (SMD), especificamente o GeoGebraGroups. Assim, o objetivo da pesquisa é investigar como a visualização pode ser uma ferramenta de aprendizagem epistêmica ao utilizar o potencial didático de uma SMD para revisitar conceitos sobre transformações lineares bidimensionais.

\section{Sobre o papel da visualização na aprendizagem}

Conforme Flores, Wagner e Buratto (2012), ao acrescentar a visualização em situações de ensino-aprendizagem em Matemática, pode-se abranger uma quantidade maior de assuntos e promover-se a intuição e o entendimento, "permitindo que os estudantes não somente aprendam matemática, mas também se tornem capazes de construir sua própria matemática" ( $p$. $35)$.

Segundo Guzman (2002, p.10) a "visualização, tem sido uma técnica geralmente usada pelos matemáticos mais criativos de todos os tempos. Alguma imagem sempre acompanha as lucubrações matemáticas, mesmo as mais abstratas". O mesmo autor complementa dizendo que

\footnotetext{
a visualização(...) teve um papel muito importante no desenvolvimento da matemática. E assim deveria ser, dada a estrutura peculiar do conhecimento humano, fortemente condicionada a elementos visuais, intuitivos, simbólicos, representativos, e dada a natureza da matemática e seus propósitos de obter uma imagem, o mais precisa possível, do mundo ao nosso redor (GUZMAN, 2002, p.10, tradução nossa).
}

Ou seja, a visualização tem um papel importante no desenvolvimento da compreensão e do pensamento matemático, pois permite fazer uma ponte entre o pensamento concreto e o abstrato. Para Leivas (2009) apud Oliveira e Leivas (2017, p.110), visualização significa o "processo de formar imagens mentais, com a finalidade de construir e comunicar determinado conceito matemático, com vistas a auxiliar na resolução de problemas analíticos ou geométricos."

Marmolejo-Avenia, Guzmán e Insuaty (2015) afirmam que a visualização desempenha um papel fundamental na apreensão dos fenômenos que compreendem a aprendizagem e o ensino de Matemática. No entanto, não é apenas uma questão de observação imediata e simples, 
mas de processamento de informações cuja complexidade deve ser descrita (MARMOLEJOAVENIA, GUZMÁN e INSUATY, 2015)

Quanto ao papel epistemológico da visualização, Giaquinto (2007) indica que sua principal preocupação não é se um diagrama ou uma imagem pode justificar uma prova matemática ou esboçar um conceito, mas se a percepção de um diagrama ou imagem pode desempenhar um papel na obtenção de conhecimento. $\mathrm{O}$ autor ainda considera a questão de saber se a visualização possibilita descobrir conhecimento matemático. Nesse caso, a palavra descobrir é usada no sentido técnico, para descrever um processo que não é apenas confiável e epistemicamente racional, mas também independente.

Zimmermann e Cunningham (1991) apud Flores, Wagner e Buratto (2012, p.34) definem visualização matemática como "o processo de formação de imagens (mentais, ou com lápis e papel, ou com o auxílio de tecnologias) usando essas imagens de forma eficaz para a descoberta e compreensão da matemática."

Ainda que as ferramentas ditas tradicionais, como a régua e o compasso, possam auxiliar na visualização de muitas figuras geométricas, os softwares ou aplicativos permitem visualizar não somente a imagem estática, mas também as relações que estas estabelecem. Isso se aplica, ainda, às construções à mão livre, como as realizadas no esboço de representações gráficas, por exemplo, ao trabalhar com gráficos de funções ou com a representação geométrica das transformações lineares. Nesse caso, ao usar um software de matemática dinâmica, é permitido observar sua movimentação além da figura estática.

\section{Sobre o GeoGebra}

O Geogebra é um software multiplataforma que apresenta versão em português e possui interface amigável. Além disso, tem-se a viabilidade de combinar geometria, álgebra, tabelas, gráficos e estatística. Por essa característica, atualmente ele é denominado um software de matemática dinâmica (HALBERSTADT, DE ASSUMPÇÃO e MATHIAS, 2018). Utilizando a ferramenta WaybackMachine ${ }^{2}$, foi possível verificar que o GeoGebra possui o domínio geogebra.org desde o ano de 2016. A Figura 1 ilustra um resgate da página inicial que o site possuiu em 2006 e 2010.

Figura 1 - Tela de entrada do site Geogebra em 2006 e 2010

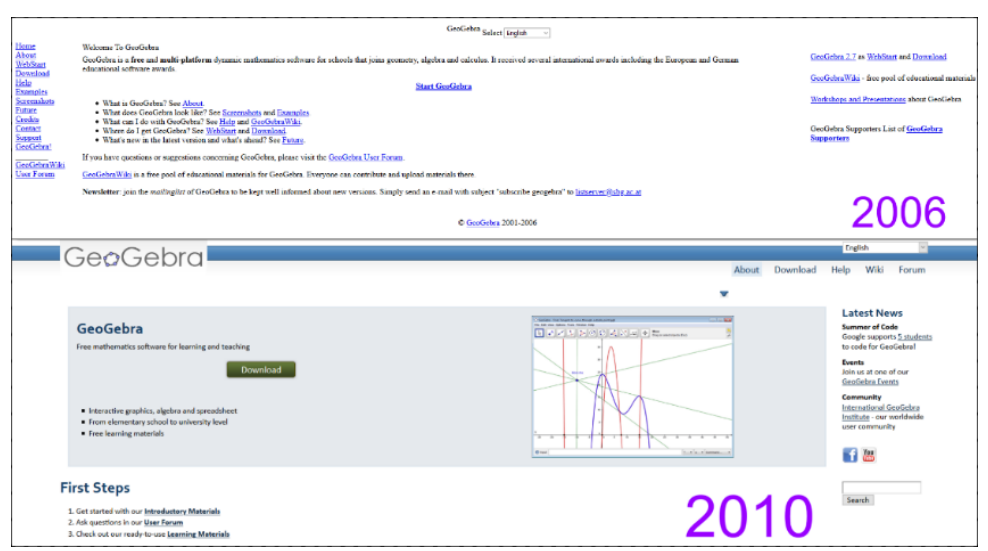

Fonte: Elaborado pelo(s) autor(es), 2019.

${ }^{2}$ https://archive.org/web/ 
Quando comparada à Figura 1, é possível observar que a Figura 2, apresentada a seguir, registra uma diferença quanto ao layout do site, por conta da inserção de aplicativos para dispositivos móveis, ocorrida em meados de 2015.

Figura 2 - Tela de entrada do site Geogebra em 2015

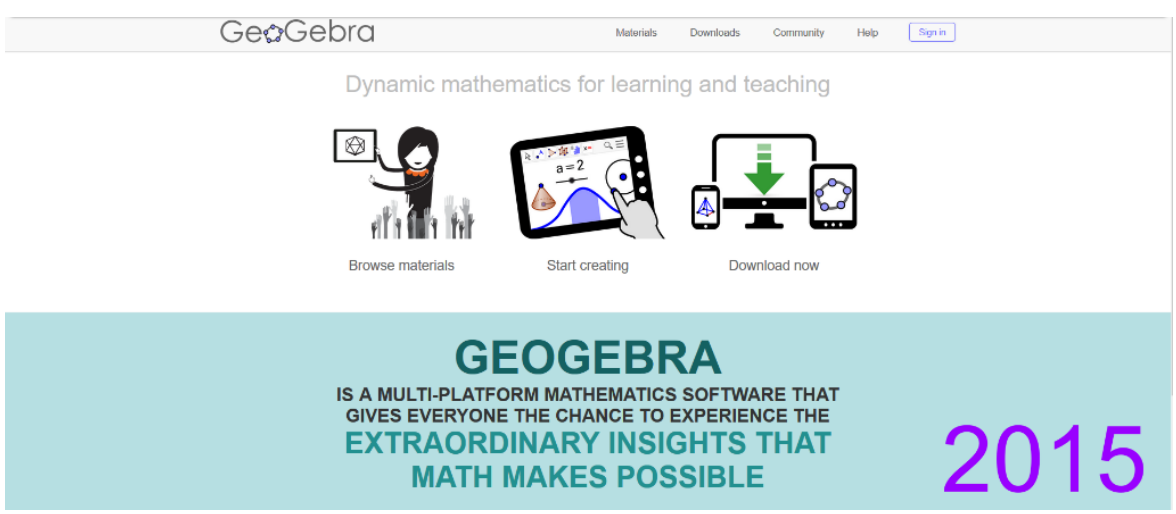

Fonte: Elaborado pelo(s) autor(es), 2019.

Hoje em dia, o site oficial do software possui outros elementos além dos materiais, da comunidade e dos downloads. A Figura 3 ilustra a tela inicial atual da página.

Figura 3 - Tela de entrada do site Geogebra em 2019

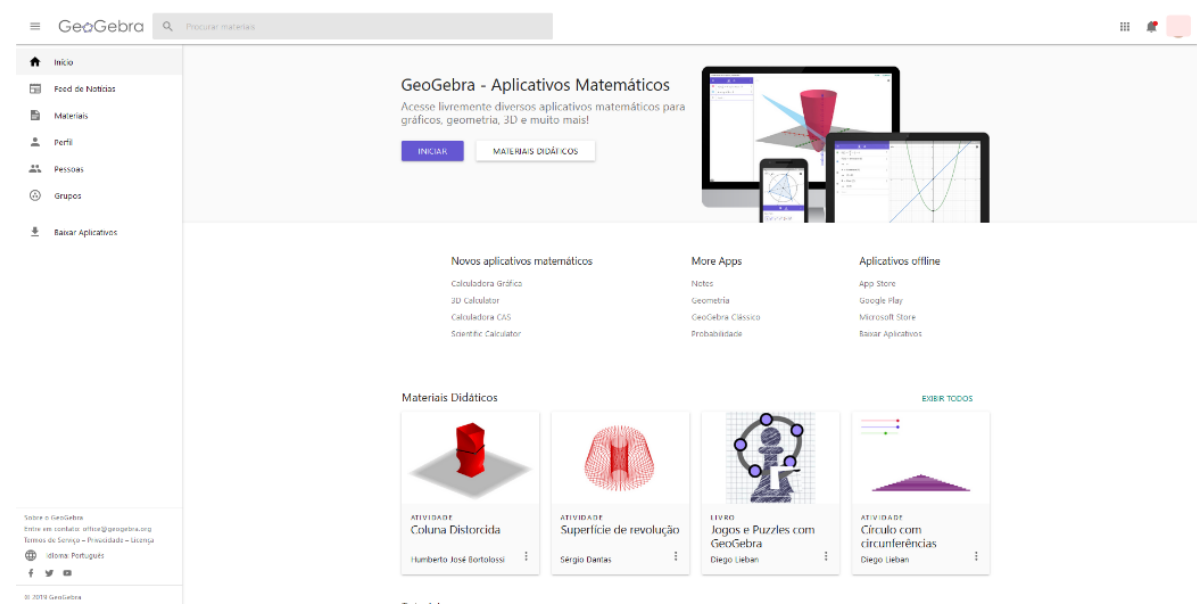

Fonte: Elaborado pelo(s) autor(es), 2019.

Nota-se que, nessa versão, há um menu lateral, onde é possível acessar as notícias, os materiais, o perfil do usuário, as pessoas que fazem parte da comunidade e os grupos. É viável, também, baixar aplicativos nesse mesmo local.

Com essa configuração, pode-se dizer que o site do Geogebra, mais especificamente o GeoGebra Groups (Grupos), é uma plataforma virtual que permite aos professores e alunos cooperarem em algumas tarefas e interagirem como em uma sala de aula virtual (DOS SANTOS e TROCADO, 2016). Embora as tarefas editáveis do GeoGebra também possam ser colocadas 
em outras plataformas, por exemplo, na plataforma Moodle (como recursos do próprio software), ela requer a instalação e atualização do plug-in apropriado, o que nem sempre é permitido.

Os grupos do GeoGebra funcionam de uma forma simples e direta. Cria-se um grupo usando a opção Grupos do menu (Figura 4) e, em seguida, é fornecido o seu código aos usuários (convidados) que irão utilizá-lo.

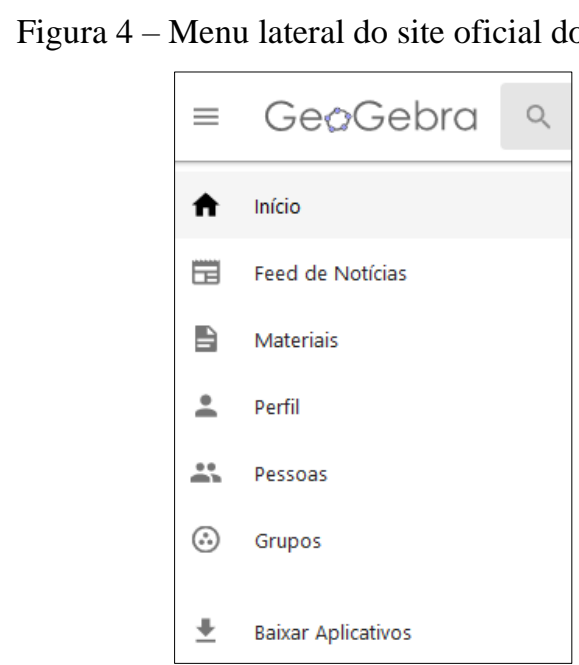

Fonte: Elaborado pelo(s) autor(es), 2019.

Por meio do fórum presente na ferramenta, é possível compartilhar com os convidados imagens, arquivos PDF, links de filmes, atividades individuais, capítulos de livros ou livros (GeoGebra Books) produzidos dentro do sistema. Utilizando a ferramenta GeoGebra Groups, é viável enviar tarefas para que os convidados executem, fornecer feedback sobre as soluções apresentadas e realizar comentários sobre postagens, organizando, dessa forma, um tipo de sistema de matemática dinâmica ou um ambiente virtual de aprendizagem. Conforme Dos Santos e Trocado (2016),

essa plataforma pode funcionar como uma sala de aula virtual onde o professor pode postar tarefas ou perguntas (perguntas de múltipla escolha ou abertas) e fornecer aos alunos algum feedback sobre sua resolução. A plataforma GeoGebra Groups pode ser impulsionada pelo GeoGebra Books que, como o nome diz, são livros virtuais formados por conteúdo estático e interativo como GeoGebra Applets and Videos. Tudo isso junto na mesma plataforma pode significar uma interação muito diferente da sala de aula tradicional (DOS SANTOS e TROCADO,2016, p. 19)

Alguns membros da comunidade do GeoGebra também utilizam o GeoGebra Groups para compartilhar ideias interessantes sobre soluções para problemas específicos, postando sobre um determinado tópico.

\section{Procedimentos metodológicos}

Este trabalho resulta de uma oficina, cujos sujeitos participantes foram professores de Matemática, alunos da disciplina de Fundamentos de Álgebra Linear e Geometria Analítica de um curso de pós-graduação (mestrado e doutorado) de uma universidade privada do interior do estado do Rio Grande do Sul. 
O espaço de trabalho foi a sala de aula, onde os alunos utilizaram seus próprios computadores conectados à internet. A oficina foi programada para ter a duração de 03 horas, durante o horário de aula da referida disciplina, no início do $1^{\circ}$ semestre de 2019. Participaram da atividade cinco alunos, referidos neste trabalho por A1, A2, A3, A4 e A5.

Para a organização das tarefas, foi construído um grupo no SMD, e os convites e código de utilização, previamente enviados aos alunos, via $e$-mail, observando-se que, para entrar no grupo, é preciso possuir um perfil no site.

Para a análise das tarefas, foram utilizadas as respostas dos alunos, além de uma entrevista realizada com cada um deles ao final da oficina, quando os questionamentos giraram em torno de suas percepções sobre tais atividades.

\section{Sobre as tarefas propostas}

Como os participantes da oficina eram professores de Matemática, acreditava-se que todos possuíam conhecimentos sobre transformações lineares. Dessa forma, foram concebidas tarefas cujo objetivo era explorar as percepções visuais desses estudantes acerca do tópico escolhido. A elaboração das tarefas, em um primeiro momento, deu-se via um GeoGebra Book, o qual foi criado exclusivamente para a oficina (Figura 5).

Figura 5 - Geogebra Book criado para a oficina

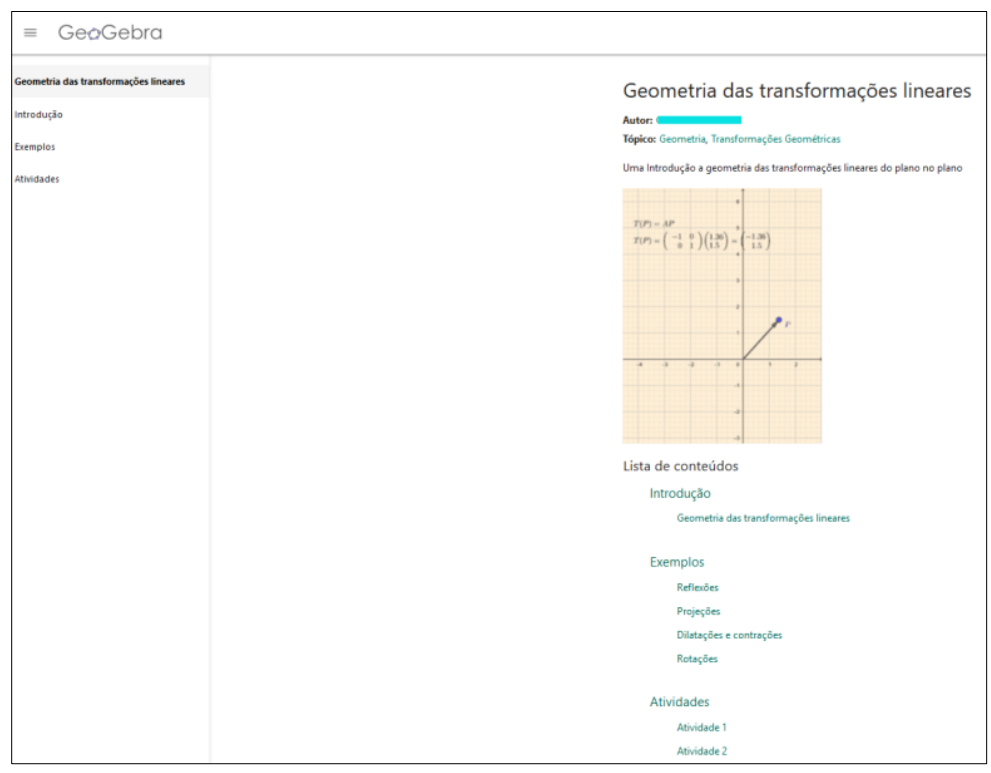

Fonte: Elaborado pelo(s) autor(es), 2019.

Após a confecção do GeoGebra Book, foi criado o grupo, no qual as atividades foram disponibilizadas. A Figura 6 ilustra o cabeçalho do grupo criado. 
Figura 6 - Cabeçalho do Grupo

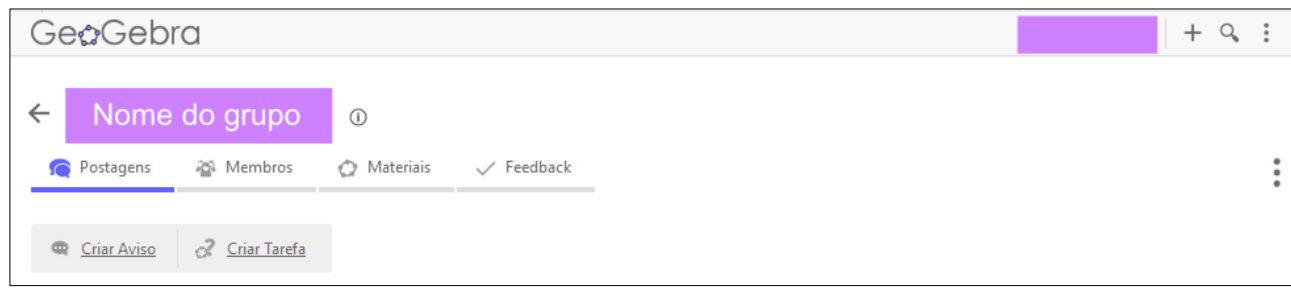

Fonte: Elaborado pelo(s) autor(es), 2019.

Observa-se que os alunos não tiveram acesso diretamente ao GeoGebra Book criado, mas aos capítulos, um de cada vez, por meio do grupo (Figura 7).

Figura 7 - Corpo do Grupo

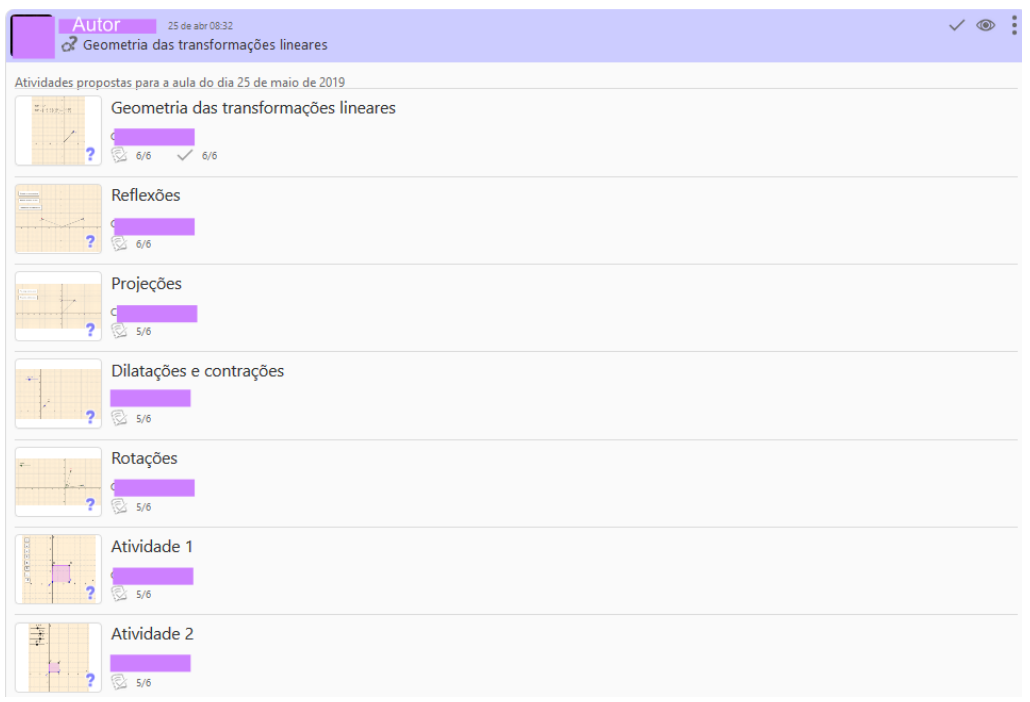

Fonte: Elaborado pelo(s) autor(es), 2019.

Conforme mencionado anteriormente, no SMD utilizado é possível fornecer feedback sobre as soluções apresentadas e comentar as postagens dos estudantes. Para tanto, basta entrar no Grupo e clicar na aba Feedback, de forma que, nesse espaço, fiquem disponibilizadas todas as respostas dos participantes, como ilustra a Figura 8. 
Figura 8 - Aba feedbak do GeoGebra Groups

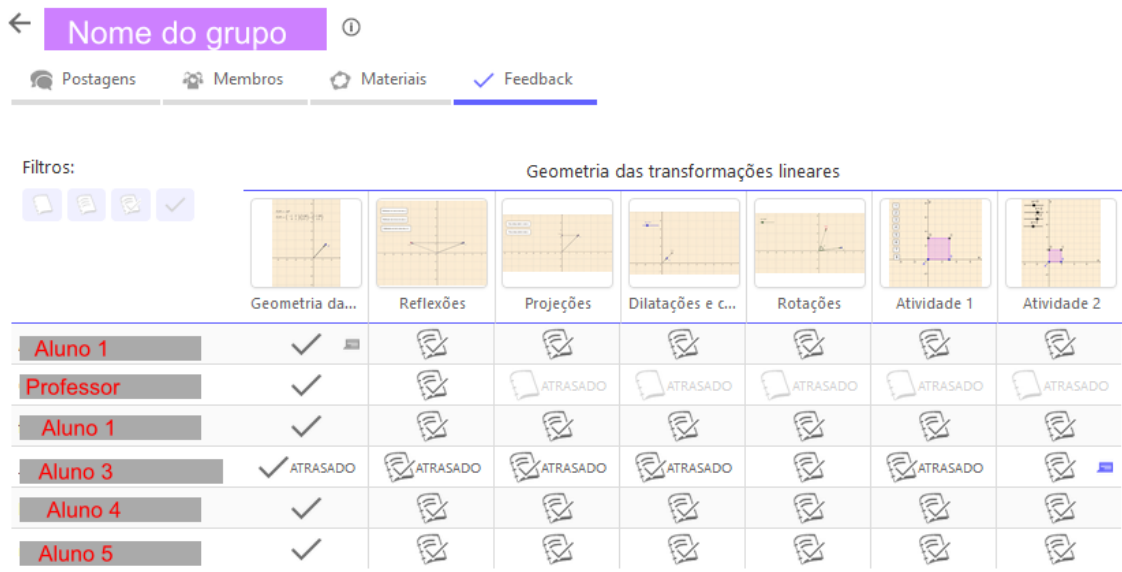

Fonte: Elaborado pelo(s) autor(es), 2019.

Para visualizar as respostas ou dar um retorno aos alunos, é necessário clicar na célula da tabela correpondente à questão e ao aluno. No caso da oficina ministrada, todos os alunos responderam a todas as questões. Optou-se por categorizar as respostas de cada questão, observando o quanto a visualização influenciou nas respostas fornecidas pelos estudantes.

A primeira tarefa teve como objetivo verificar qual o entendimento dos estudantes sobre transformações lineares. Ela era composta por dois applets e quatro questões (Figura 9).

Figura 9 - Primeira tarefa proposta

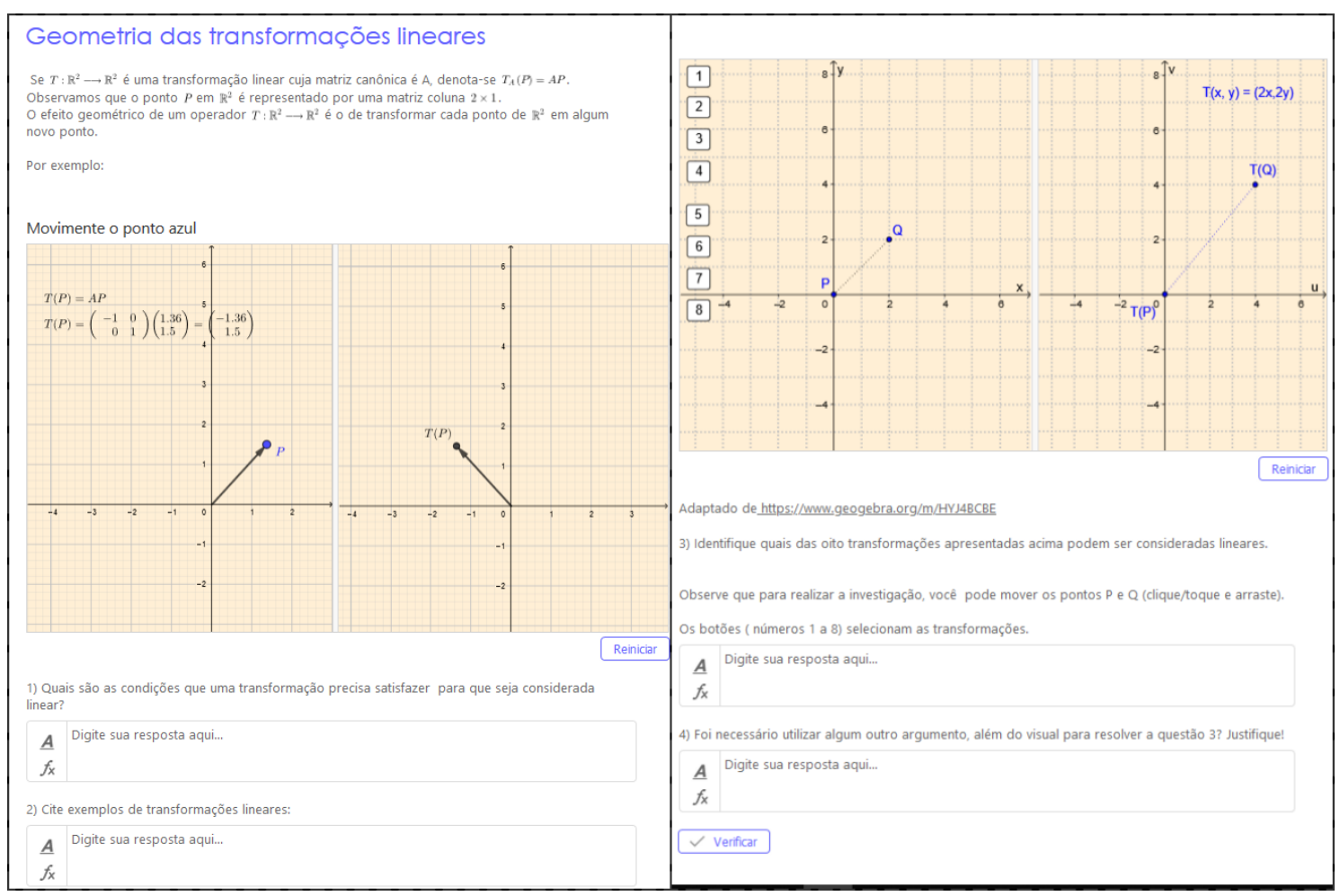

Fonte: Elaborado pelo(s) autor(es), 2019. 
Observa-se que, apesar de todos os participantes serem professores e licenciados em Matemática, apenas um deles soube responder com precisão as duas primeiras questões (Figura 10).

Figura 10 - Resposta do aluno A5 aos itens 1 e 2 da tarefa 1

\begin{tabular}{|c|c|}
\hline \multicolumn{2}{|r|}{$\begin{array}{l}\text { 1) Quais são as condições que uma transformação precisa satisfazer para que seja considerada } \\
\text { linear? }\end{array}$} \\
\hline$\underline{\boldsymbol{A}}$ & $T(u+v)=T(u)+T(v), \forall u, v$ no Espaço vetorial \\
\hline$f_{x}$ & 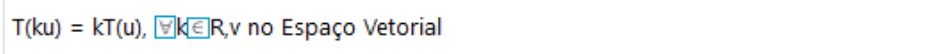 \\
\hline \multicolumn{2}{|c|}{ 2) Cite exemplos de transformações lineares: } \\
\hline $\begin{array}{l}\underline{\boldsymbol{A}} \\
f_{x}\end{array}$ & rotações, cisalhamento. \\
\hline
\end{tabular}

Fonte: Elaborado pelo(s) autor(es), 2019.

Para ambos os itens, os demais alunos responderam que não lembravam, não sabiam ou escreveram respostas incompletas.

Observa-se que, diferentemente do que foi pensado, o applet que continha um exemplo de transformação linear e duas representações desta (uma geométrica e outra na forma matricial) não foi suficiente para sugerir a ideia ou fazer com que os estudantes lembrassem das condições que uma transformação precisa satisfazer para ser linear. Além disso, os participantes não forneceram exemplos de transformações lineares, algo que também é solicitado na atividade.

Os terceiro e quarto itens da tarefa 1 não apresentaram evolução significativa nas respostas. Os alunos A1 e A2 continuaram com a mesma resposta: "não sei". O aluno A4, nitidamente, não teve ideia do que é uma transformação linear, pois suas respostas giraram em torno do primeiro applet. O aluno A5 respondeu corretamente aos dois itens. O aluno A3 respondeu ao item 3 com uma solução parcialmente correta, justificando o seu erro no item 4, conforme ilustra a Figura 11.

Figura 11 - Resposta do aluno A4 aos itens 3 e 4 da tarefa 1

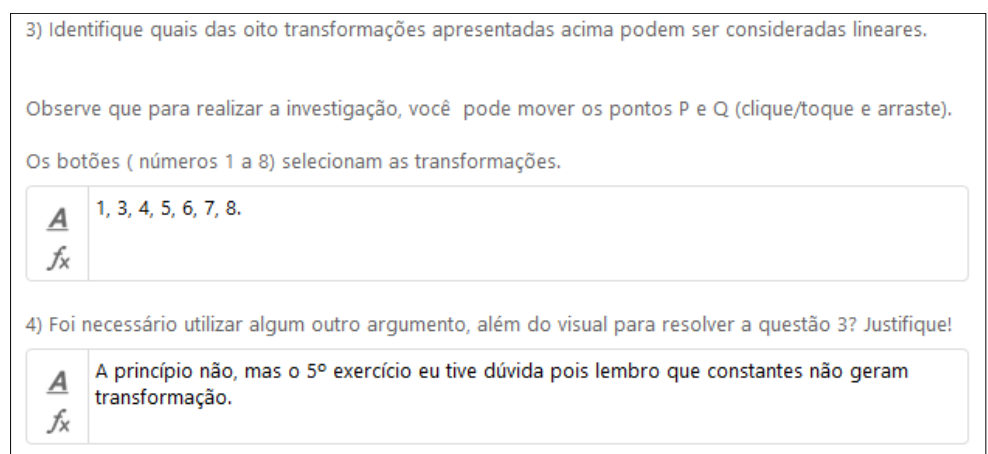

Fonte: Elaborado pelo(s) autor(es), 2019.

No espaço destinado aos comentários, o aluno A1 forneceu um dado relevante para o contexto da pesquisa como ilustra a Figura 12. 
Figura 12 - Comentário do aluno A1

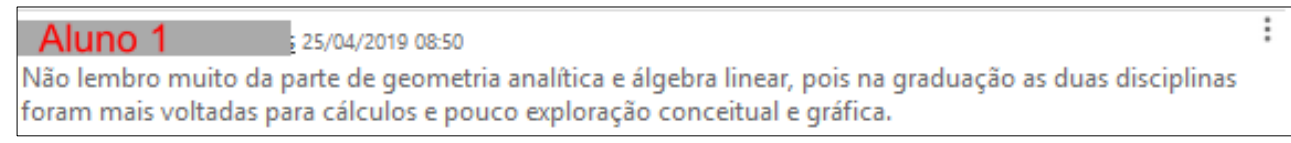

Fonte: Elaborado pelo(s) autor(es), 2019.

Segundo a informação dada pelo aluno A1 no SMD, e posteriormente na entrevista, foi possível perceber que, durante a sua graduação, a percepção visual não foi muito explorada, pelo menos não na disciplina de Álgebra Linear. Olhando para tal comentário e para as respostas dadas pelos estudantes, fica-se em dúvida sobre o quanto foi, de fato, apreendido sobre transformações lineares durante a graduação.

Além disso, entende-se serem as imagens, efetivamente, importantes no processo de aprendizagem, o que nem sempre é percebido pelos professores que lecionam tal disciplina, segundo a experiência dos autores. A visualização deve ser manipulada, ou seja, "transformada" e "convertida" de tal forma que sirva como uma base viável para o desenvolvimento de um argumento matemático, a fim de que os estudantes possam ser guiados para isso.

Presmeg (2006, p.25) refere-se a esta última ideia da seguinte forma: "Como os professores podem ajudar os alunos a fazer conexões entre imagens e inscrições visuais idiossincráticas e processos e notações matemáticos convencionais?” Ainda, Flores et al. (2012) afirmam que é necessário os professores utilizarem processos visuais nas situações de ensinoaprendizagem, pois isso fará com que os alunos consigam ter um maior entendimento dos conceitos envolvidos no processo.

As tarefas 2, 3, 4 e 5 tratavam de reflexões, projeções, dilatações ou contrações e rotações, respectivamente. Todas foram planejadas com o intuito de verificar o quanto visualização da representação geométrica auxiliaria aos alunos a representar a transformação na sua forma analítica ou matricial.

Para analisar as respostas dos alunos, foi elaborado o Quadro 1, no qual, em um primeiro momento, as respostas foram classificadas como corretas (C), não respondeu $(\mathrm{N})$ e incorretas (I). Os alunos foram identificados por seus números (Ai indica o Aluno i, com i=1,2,3,4,5), e as tarefas foram indicadas de acordo com as questões ( $\mathrm{Tj}$ indica a tarefa $\mathrm{j}$, com $\mathrm{j}=2,3,4 \mathrm{e} 5$ ).

Quadro 1 - Classificação das respostas dos alunos às tarefas 2 a 5

\begin{tabular}{|c|c|c|c|c|c|}
\hline & A1 & A2 & A3 & A4 & A5 \\
\hline T2 Questão 1 & I & C & C & I & C \\
\hline T2 Questão 2 & I & C & C & I & C \\
\hline T3 Questão 1 & I & C & C & I & C \\
\hline T3 Questão 2 & I & C & C & I & C \\
\hline T4 Questão 1 & C & C & C & I & C \\
\hline T4 Questão 2 & C & C & C & I & C \\
\hline T4 Questão 3 & C & C & C & I & C \\
\hline T5 Questão 1 & C & C & C & C & C \\
\hline
\end{tabular}

Fonte: Elaborado pelo(s) autor(es), 2019.

A Figura 13 ilustra a segunda tarefa e aborda a transformação conhecida por reflexão. Ela difere das demais por trazer um exemplo. 
Figura 13 - Início da tarefa 2

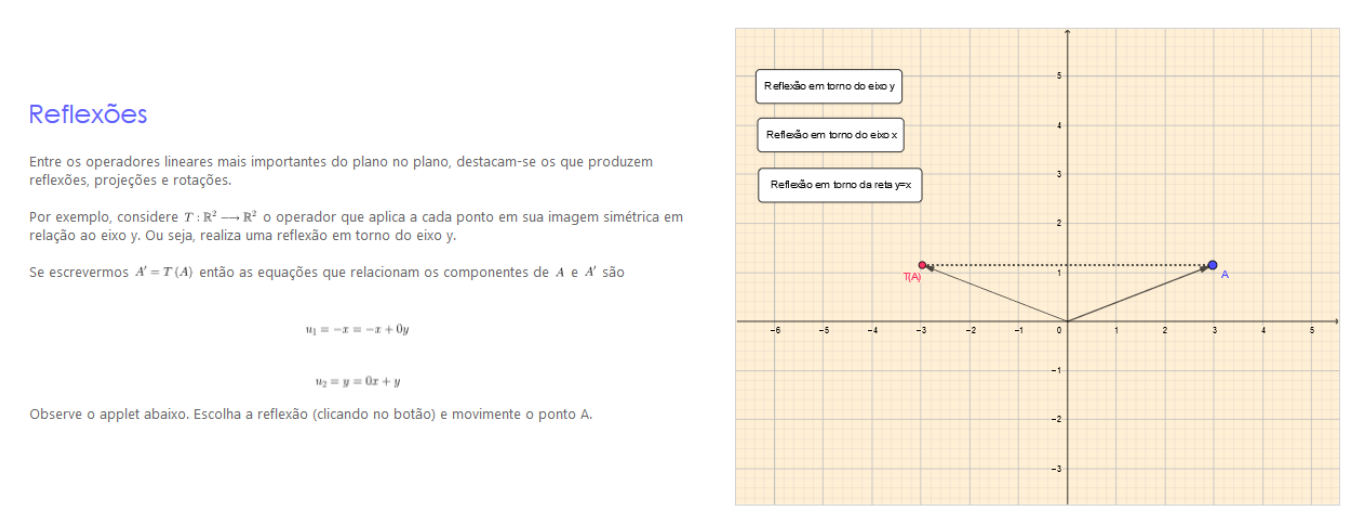

Fonte: Elaborado pelo(s) autor(es), 2019.

As questões se referiam às equações das outras duas transformações do tipo reflexões, não apresentadas no exemplo. Para visualizá-las, o aluno deveria clicar no botão correspondente. Observa-se que três alunos responderam aos questionamentos de forma correta. Os alunos A1 e A4 responderam de forma incorreta. A resposta do aluno A4 chamou a atenção pelo fato de misturar pontos e variáveis (Figura 14).

Figura 14 - resposta do aluno A4 aos itens 1 e 2 da tarefa 2

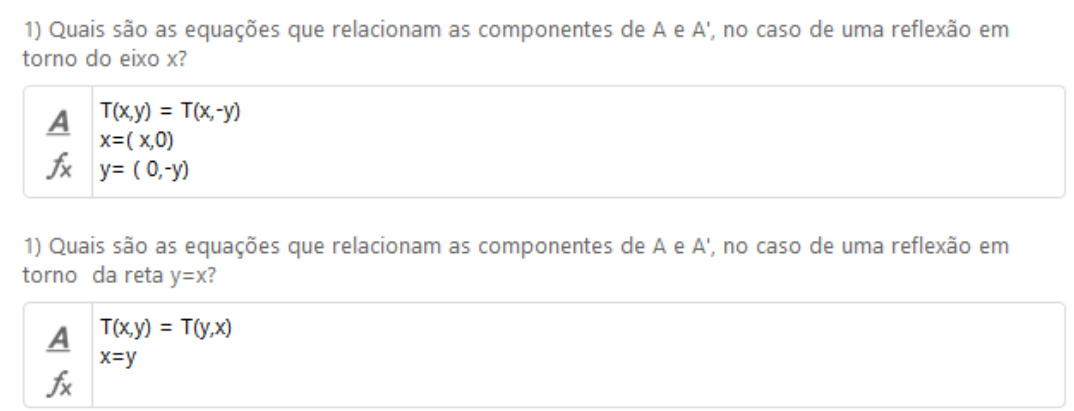

Fonte: Elaborado pelo(s) autor(es), 2019.

Ao responder quais eram as equações que relacionavam as componentes do ponto A e da respectiva imagem pela transformação, não foi possível compreender o significado que o aluno atribuiu à expressão $\mathrm{x}=(\mathrm{x}, 0)$, visto que, matematicamente, ela não tem nenhum sentido. Ao ser questionado sobre sua resposta, ele disse não ter conseguido compreender o que estava sendo solicitado.

Nota-se, nesse caso, que a visualização, a manipulação dos elementos geométricos e o exemplo não foram suficientes para auxiliar o aluno na compreensão dos conceitos que certamente já conhecia. A terceira tarefa (Figura 15) tratava das transformações do tipo projeções. 
Figura 15 - Tarefa sobre projeções

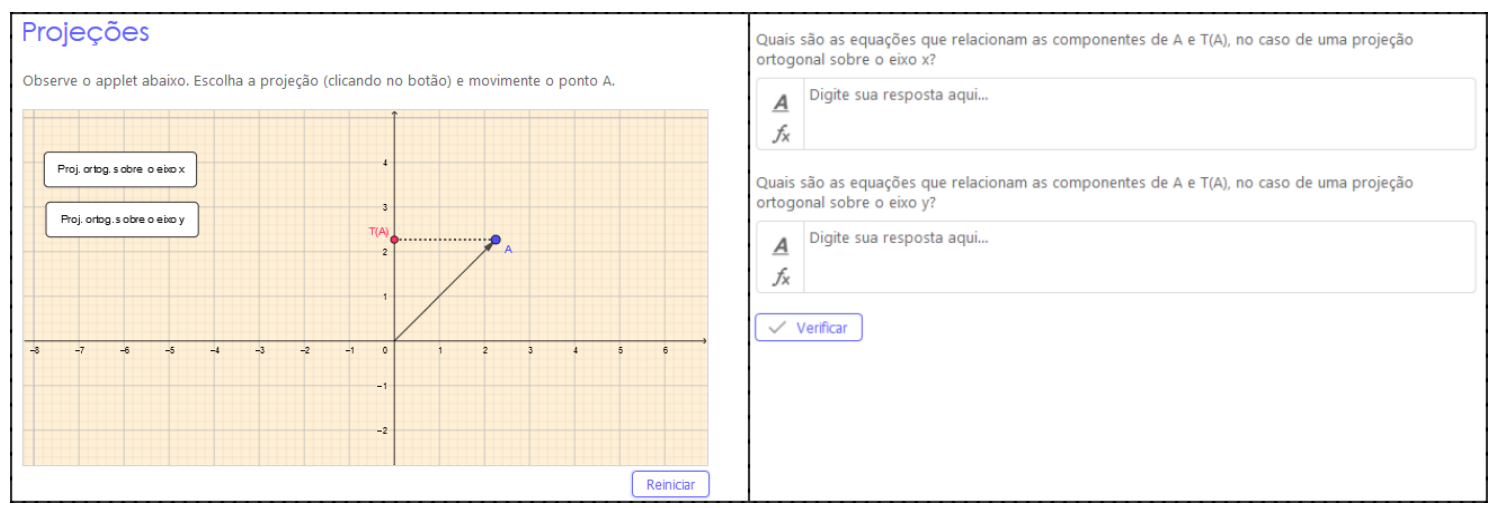

Fonte: Elaborado pelo(s) autor(es), 2019.

Os alunos A2, A3 e A5 responderam corretamente aos questionamentos realizados. Os alunos 1 e 4 tiveram dificuldade na resolução da tarefa. O aluno A1 (Figura 16) afirmou existir duas leis para cada transformação.

Figura 16 - Resposta do aluno A1 à tarefa 3

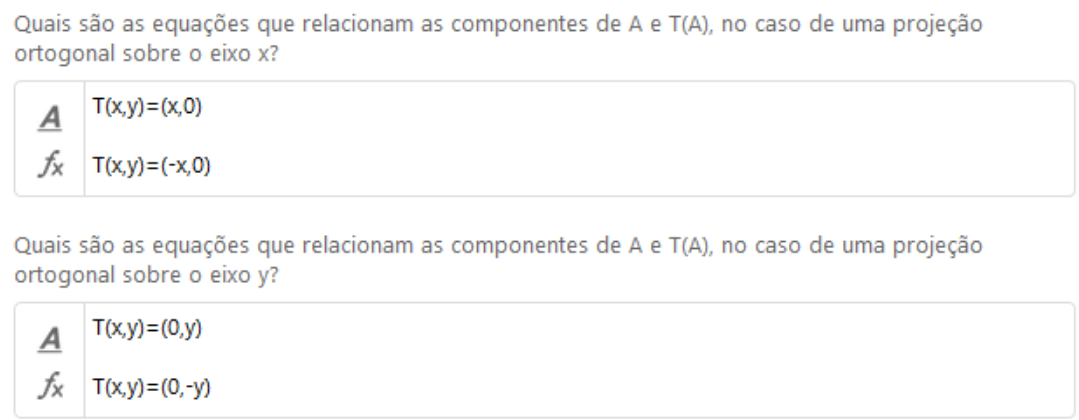

Fonte: Elaborado pelo(s) autor(es), 2019.

Observa-se que o aluno considerou existir diferença entre os eixos positivo e negativo. $\mathrm{Na}$ entrevista, ele disse que teve a impressão de que seria necessário realizar essa distinção ao movimentar os pontos. Nesse caso, reitera-se o indicado por Giaquinto (2007) no que diz respeito à visualização favorecer ou justificar uma prova ou o esboço de um conceito. Para essa tarefa, destaca-se a resposta dada pelo aluno A5 (Figura 17), pelo fato de que, na atividade anterior, o estudante não tinha conseguido entender o que era solicitado. 
Figura 17 - Resposta do aluno A5 à tarefa 3

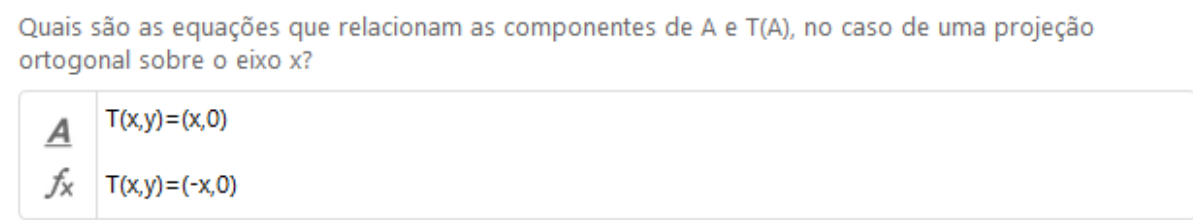

Quais são as equações que relacionam as componentes de $A$ e $T(A)$, no caso de uma projeção ortogonal sobre o eixo y?

$$
\begin{array}{l|l}
\underline{A} & \mathrm{~T}(\mathrm{x}, \mathrm{y})=(0, \mathrm{y}) \\
f_{x} & \mathrm{~T}(\mathrm{x}, \mathrm{y})=(0,-\mathrm{y})
\end{array}
$$

Fonte: Elaborado pelo(s) autor(es), 2019.

Para essa tarefa, A5 contou com o auxílio do professor, que procurou fazer ele perceber o que ocorria com os pontos ao serem movimentados. Na entrevista, esse aluno afirmou ter apenas reproduzido alguns exemplos, não percebendo o que, de fato, estava ocorrendo.

Observa-se que as tarefas 4 e 5 eram muito semelhantes à tarefa 3. Todos os alunos, com exceção do A4, resolveram as questões propostas na tarefa 4 de forma correta. A4 continuou cometendo os mesmos equívocos da tarefa 3.

Nota-se, também, que todos os alunos acertaram a tarefa 5, apesar do fato de que nenhum deles, no momento da aplicação, tenha conseguido determinar de forma correta as equações. Nesse sentido, foi necessário uma intervenção do professor, relembrando as equações da transformação rotação no quadro (Figura 18).

Figura 18 - Resolução da tarefa 5 realizada pelo professor

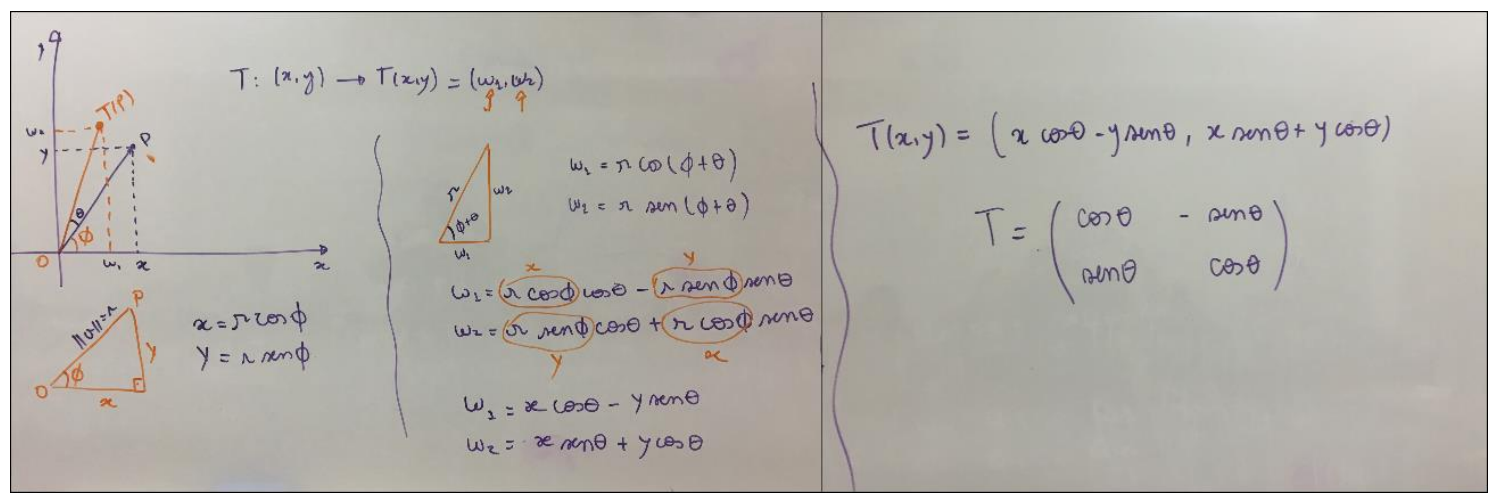

Fonte: Elaborado pelo(s) autor(es), 2019.

Para o professor (primeiro autor do trabalho) o fato de precisar deduzir as equações junto aos alunos foi uma surpresa, visto que todos eles já tinham conhecimento do conteúdo e esperavase que o applet fornecido na tarefa auxiliasse na dedução das equações. Nesse caso, foi utilizado

[...] um método visual de solução é aquele que envolve imagens visuais, com ou sem diagrama, como parte essencial do método de solução, mesmo se métodos de raciocínio ou algébricos também forem empregados. Um método de solução não visual é aquele que não envolve imagens visuais como parte essencial do método de solução (PRESMEG, 1986, p.298, tradução nossa) 
A tarefa de número 6 tinha por objetivo visualizar o comportamento das transformações lineares, observando seu efeito nos pontos de figuras no plano. Para isso, foi disponibilizado um applet que continha 8 opções de transformações de um quadrado dado (Figura 19).

Figura 19-Applet disponibilizado na tarefa 6

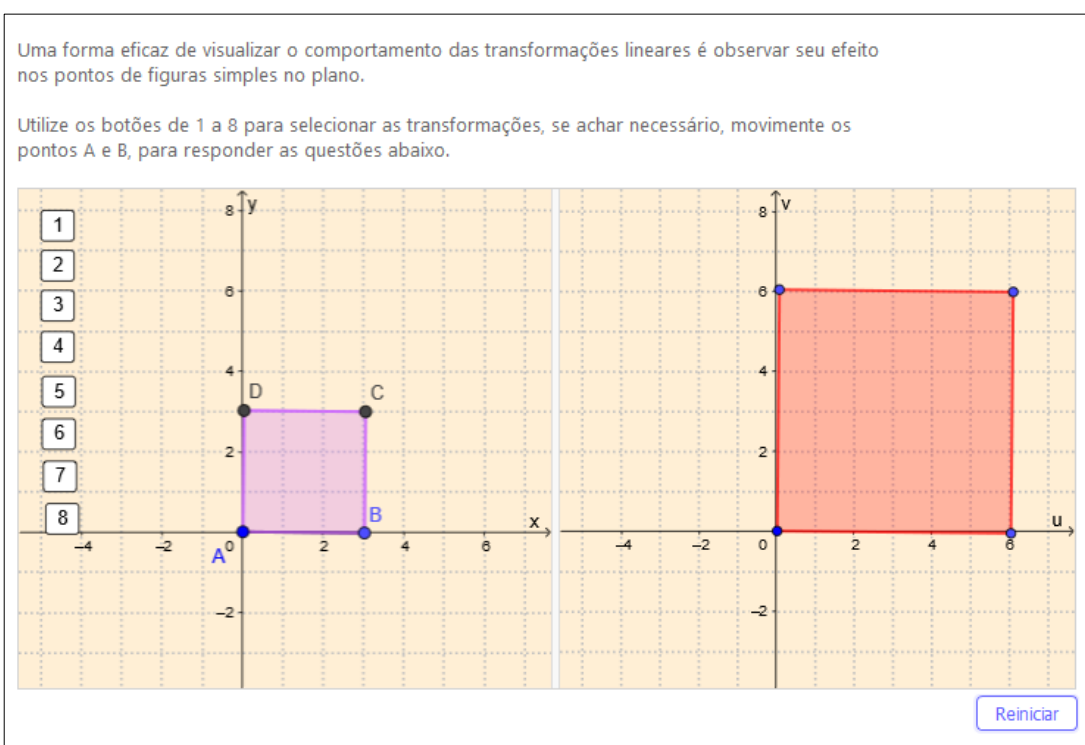

Fonte: Elaborado pelo(s) autor(es), 2019.

Observa-se, do lado esquerdo da Figura 19, haver um quadrado de lado 3 unidades de medida. Tal elemento pode ser modificado. Ao fazê-lo (Figura 20), o quadrado do lado direito também é modificado, respeitando a transformação aplicada.

Figura 20 - Applet da tarefa 6 com modificações

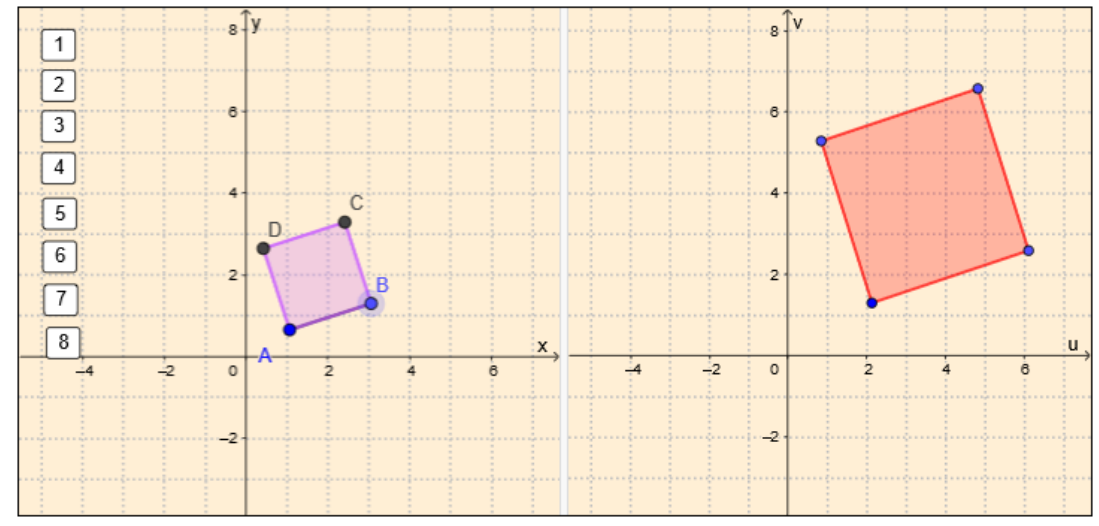

Fonte: Elaborado pelo(s) autor(es), 2019.

Como o applet possui 8 opções de escolhas (botões numerados de 1 a 8), ao clicar em cada um deles, o quadrado do lado direito é modificado via uma transformação diferente (Figura 21). 
Figura 21 - Transformações apresentadas na tarefa 6

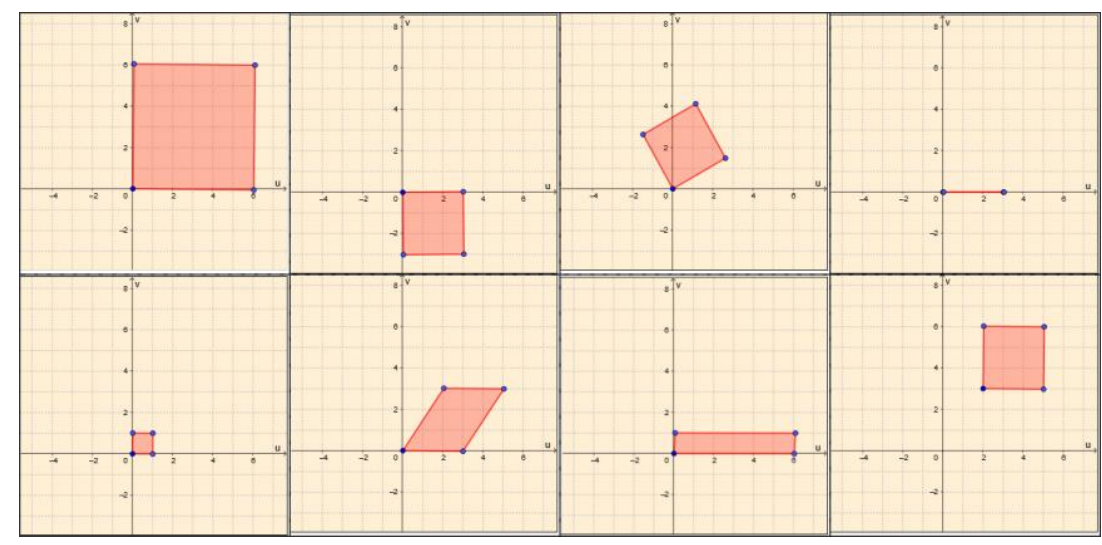

Fonte: Elaborado pelo(s) autor(es), 2019.

Após explorar o applet, o usuário deveria responder a 3 questões sobre as transformações apresentadas. Da mesma forma que foi feito para as tarefas anteriores, elaborouse o Quadro 2, que contém a classificação das respostas dadas pelos alunos às questões propostas na tarefa 6 .

Quadro 2 - Classificação das respostas dos alunos à tarefas 6.

\begin{tabular}{|l|l|l|l|l|l|}
\hline & A1 & A2 & A3 & A4 & A5 \\
\hline T6 Questão 1 & I & I & I & I & C \\
\hline T6 Questão 2 & C & C & C & C & C \\
\hline T6 Questão 3 & I & I & I & I & C \\
\hline
\end{tabular}

Fonte: Elaborado pelo(s) autor(es), 2019.

Nota-se que todos os alunos responderam o segundo item de forma correta. Acredita-se que isso possa ter ocorrido por se tratar de uma transformação relativamente fácil e já trabalhada nas tarefas anteriores. Apenas o aluno A5 respondeu corretamente aos 3 itens. As respostas dos demais alunos, para a primeira e terceira tarefas, foram muito semelhantes.

No primeiro item, os alunos não consideraram que as transformações de números 6 e 7 (cisalhamentos) eram lineares, mas observaram que a transformação 8 (translação) poderia ser classificada como tal. No terceiro item, a maioria dos alunos expressou corretamente a denominação das transformações apresentadas, com exceção da transformação 4, que era uma projeção sobre o eixo x e foi tratada como uma contração (Figura 22). 
Figura 22 - Resposta da aluna A4 aos itens da tarefa 6.

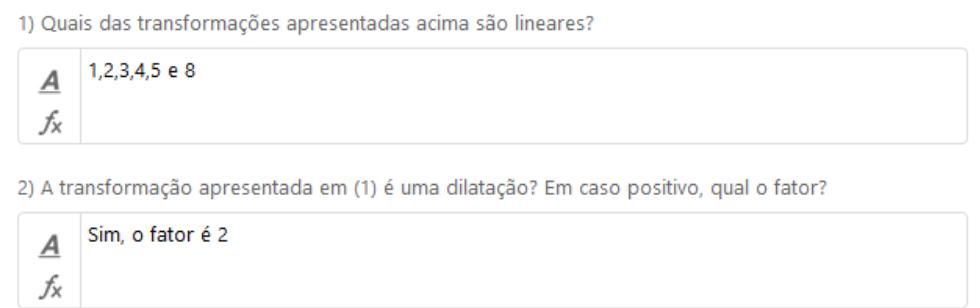

3) Considerando as transformações que são lineares, como denominam-se as transformações lineares apresentadas acima?

$$
\begin{array}{|l|l|}
\hline \underline{A} & \text { 1)dilatação } \\
\hline f_{X} & \text { 2) reflexão } \\
\text { 3) rotação } \\
\text { 4) contração } \\
\text { 5)contração } \\
\text { 8)translação }
\end{array}
$$

Fonte: Elaborado pelo(s) autor(es), 2019.

Conforme a entrevista realizada com os alunos, observa-se que, nesse caso, a visualização não foi um elemento facilitador. Segundo Giaquinto (2007), a percepção visual pode desencadear certos atos de "reconhecimento" que fazem representar as percepções com um tipo de conteúdo conceitual. Essas representações podem, então, desencadear disposições à formação de crenças, e resultam, de maneira confiável, em verdades matemáticas. Nesse caso, a maioria dos alunos não conseguiu relacionar a forma analítica das transformações à sua representação gráfica e não estabeleceu conexões suficientes para reconhecer se uma transformação é linear, utilizando-se do dinamismo e da visualização.

A última tarefa disponibilizada foi planejada em duas etapas. Em um primeiro momento, os alunos deveriam visualizar o applet disponibilizado e responder a duas questões. Essa etapa teve por objetivo verificar a necessidade de utilizar as ferramentas do applet para auxiliar a responder tais questionamentos. A primeira questão era referente à transformação dilatação (que já havia sido explorada na tarefa anterior), e a segunda era relativo à transformação reflexão (que também já havia sido explorada na tarefa 2).

A segunda etapa da tarefa era referente a transformação linear cisalhamento, conceito que ainda não havia sido formalizado na oficina. Nesse sentido, foi disponibilizada a definição e solicitado que os alunos respondessem a três questões, sendo duas de múltipla escolha.

Novamente, elaborou-se um quadro (Quadro 3) onde as respostas dos alunos foram classificadas para posterior análise.

Quadro 3 - Classificação das respostas dos alunos à tarefa 7

\begin{tabular}{|l|l|l|l|l|l|}
\hline & A1 & A2 & A3 & A4 & A5 \\
\hline T7 Questão 1 & C & C & C & C & C \\
\hline T7 Questão 2 & I & I & C & I & C \\
\hline T7 Questão 3 & I & C & C & I & C \\
\hline T7 Questão 4 & I & I & I & I & C \\
\hline T7 Questão 5 & I & I & I & I & C \\
\hline T7 Questão 6 & N & N & N & N & C \\
\hline
\end{tabular}

Fonte: Elaborado pelo(s) autor(es), 2019.

A Figura 23 ilustra os dois primeiros itens da tarefa 7 e o applet fornecido. 
Figura 23 - Itens 1 e 2 da tarefa 7

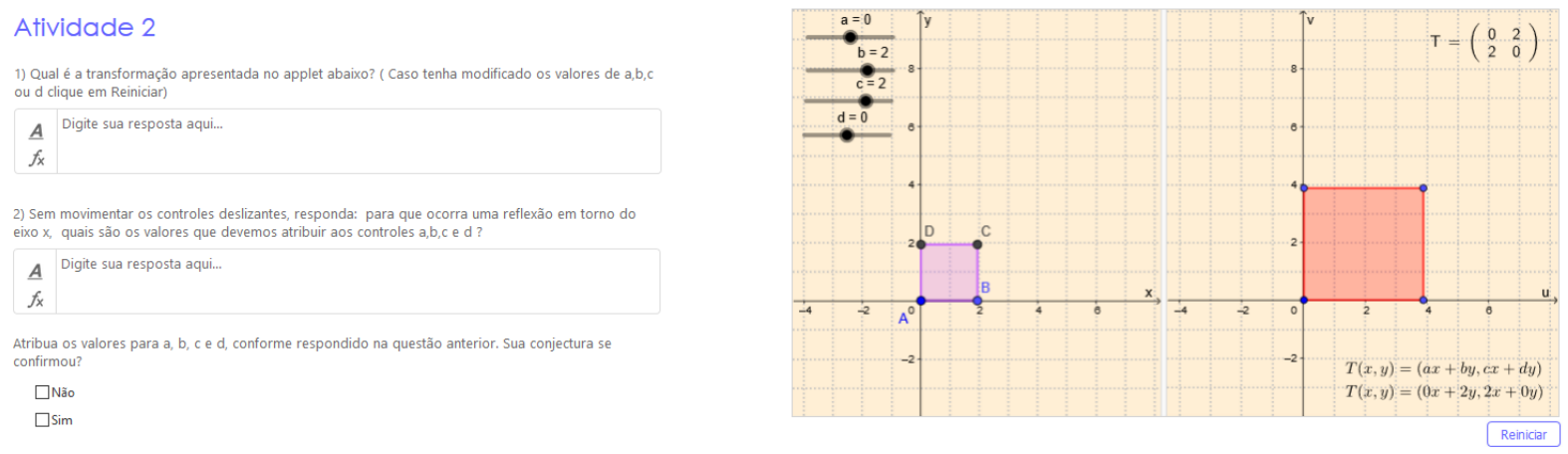

Fonte: Elaborado pelo(s) autor(es), 2019.

Todos os alunos responderam de forma correta ao primeiro item, e apenas os alunos A2 e A5 responderam ao segundo item da mesma forma. Os alunos A1, A2 e A4 não conseguiram expressar os valores de $\mathrm{a}, \mathrm{b}, \mathrm{c}$ e d adequadamente e, como consequência, a conjectura firmada no item não se confirmou.

$\mathrm{Na}$ resolução dos itens 3 e 4, esperava-se que os alunos manipulassem o applet e respondessem (corretamente) às questões. Durante a oficina, percebeu-se que isso não ocorreu. Os alunos tentaram antever as respostas, marcando qualquer alternativa (Figura 24).

Figura 24 - Resposta do aluno A1 aos itens 3 e 4 da tarefa 7

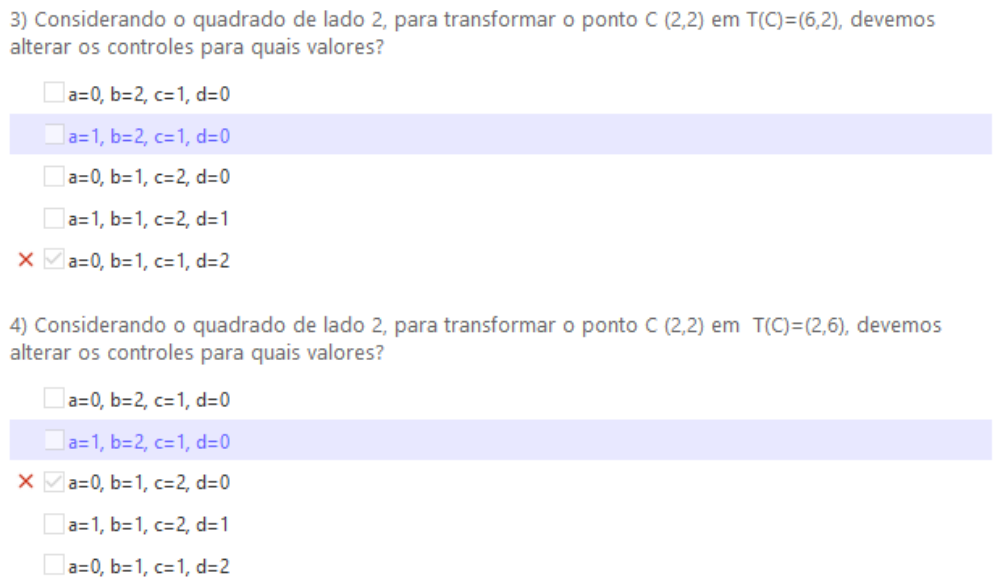

Fonte: Elaborado pelo(s) autor(es), 2019.

Os itens 5 e 6 da tarefa 7 tinham o objetivo de conhecer um pouco mais sobre a formação inicial dos participantes da oficina, bem como verificar suas percepções quanto ao conceito revisado. $\mathrm{O}$ aluno $\mathrm{A} 5$, que respondeu de forma correta a todas as questões, foi o único a responder de forma positiva ao questionamento realizado no item 5, além de realizar a verificação que a transformação era linear (não o fez no SMD, mas mostrou a resolução no papel). Esse aluno também foi o único a responder ao último item, como ilustra a Figura 25. 
Figura 25 - Resposta do aluno A5 aos itens 3 e 4 da tarefa 7

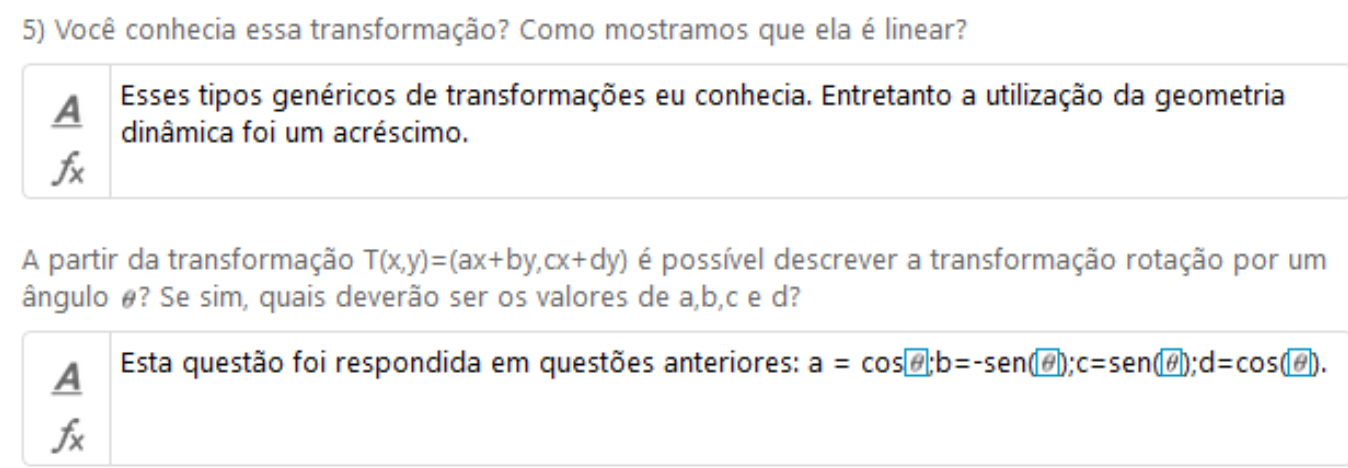

Fonte: Elaborado pelo(s) autor(es), 2019.

Observa-se que todas as tarefas propostas continham pelo menos um applet, o qual deveria ser manipulado. Nesse sentido, explorou-se a função da visualização dinâmica nas transformações, com o objetivo de investigar se a visualização, apoiada por um SMD, pode ser considerada um auxílio para a aprendizagem de transformações lineares bidimensionais.

\section{Considerações finais}

O objetivo desta pesquisa foi investigar como a visualização pode ser uma ferramenta de aprendizagem epistêmica ao utilizar o potencial didático de um Sistema de Matemática Dinâmica para revisitar conceitos sobre transformações lineares bidimensionais. Para Giaquinto (2007, p.40), uma questão central é se a visualização pode fornecer um meio confiável de obter verdades matemáticas.

Acredita-se que essa é o tipo de questão com a qual as pesquisas na área de Educação Matemática estão preparadas para lidar. Isso é apontado em estudos recentes como Stewart, Larson e Zandieh (2019) que descrevem o estado atual das pesquisas no ensino de Álgebra Linear. Os autores pontuam o uso das tecnologias e as abordagens visuais como evidências de orientações promissoras para apoiar o sucesso dos alunos por meio de intervenções de ensino e experimentos em sala aula.

Dessa forma, desenvolveu-se, neste trabalho, um conjunto de tarefas que foram projetadas para levar os sujeitos a considerarem a visualização enquanto alternativa para a resolução de tais atividades. Nesse sentido, as respostas dos alunos, tanto nas tarefas propostas quanto nas entrevistas realizadas, tornaram possível mensurar que o objetivo foi alcançado.

O planejamento da oficina utilizando o SMD escolhido, assim como o acesso dos alunos a esse sistema, não apresentaram maiores obstáculos para os participantes, fazendo com que a realização da atividade tenha transcorrido de forma relativamente estável. A utilização dos recursos ofertados no SMD, por parte dos alunos, foi feita de maneira descomplicada e intuitiva. Ao serem questionados sobre a viabilidade de utilização do SMD em sala de aula, responderam positivamente, o que confirma ter sido alcançado o objetivo da pesquisa.

Durante a realização da oficina, foi possível perceber que o tempo para o desenvolvimento de todas as atividades previstas foi pequeno. Observa-se que elas foram planejadas acreditando que os alunos, por serem licenciados em Matemática, teriam mais afinidade com o tópico escolhido. 
Nesse sentido, notou-se que a maioria dos alunos não recordava os conceitos relacionados a transformações lineares, além de possuírem muita dificuldade, principalmente em termos das notações utilizadas. Acredita-se que essa dificuldade seja oriunda do distanciamento que o tema transformações lineares apresenta com a prática de sala de aula dos sujeitos da pesquisa. Isso vai ao encontro do apontado por Silva, Alves e Almeida (2018), ao indicarem sobre o ensino na disciplina ainda manter-se de uma forma tradicional. Também, os autores recomendam a incorporação de aspectos didáticos-pedagógicos no seu desenvolvimento, o que se buscou incluir com o SMD.

Entretanto, observa-se que o único aluno que possuía conhecimento sobre transformações lineares conseguiu desenvolver as atividades no tempo previsto. Em sua entrevista, ele respondeu que o SMD o auxiliou a explorar as percepções visuais. Esse aluno também salientou que, às vezes, a ênfase no ensino de transformações lineares ocorre por meios não visuais. $\mathrm{O}$ fato dos demais não terem obtido plenamente o alcance esperado pode ser consequência da falta de explorar inovações como a aqui sugerida no ensino com o qual não estão acostumados ao longo da sua formação. Muito embora demais participantes tenham se afastado do objetivo inicial proposto, esses sujeitos tiveram um ganho considerável, pois ocorreu uma revisão de conceitos já trabalhados, os quais provavelmente terão de ensinar em sua prática profissional, tanto na escola básica ou no ensino superior o que, certamente, contribuiu para a sua formação continuada e permitirá inovar a prática profissional.

Pretende-se aplicar a mesma oficina a alunos em formação (licenciandos em Matemática) para continuar a investigação, visto a importância do conceito matemático e os achados realizados nesta pesquisa.

\section{Referências}

ANTON, Howard; RORRES, Chris. Álgebra linear com aplicações. 10.ed. São Paulo: Ed. Bookman, 2012.

BRONDINO, Nair Cristina Margarido; BRONDINO, Odney Carlos. Uma sugestão de uso de planilhas eletrônicas no ensino de transformações lineares. In: COBENGE: CONGRESSO BRASILEIRO DE EDUCAÇÃO EM ENGENHARIA, 2012.

CARDOSO, Valdinei Cezar et al. Ensino e aprendizagem de álgebra linear: uma discussão acerca de aulas tradicionais, reversas e de vídeos digitais. Tese de Doutorado. Universidade Estadual de Campinas, Faculdade de Educação. 2014. 205 fls.

DOS SANTOS, José Manuel; TROCADO, Alexandre Emanuel Batista. GeoGebra as a learning Mathematical Environment. Revista do Instituto GeoGebra Internacional de São Paulo, São Paulo, v. 5, n. 1, p.05-22, 2016.

EISENBERG, Theodore; DREYFUS, Tommy. On understanding how students learn to visualize function transformations. Research in collegiate mathematics education, v. 1, p. 45-68, 1994.

FLORES, Cláudia Regina; WAGNER, Débora Regina; BURATTO, Ivone Catarina Freitas. Pesquisa em visualização na educação matemática: conceitos, tendências e perspectivas.

Educação Matemática Pesquisa: Revista do Programa de Estudos Pós-Graduados em Educação Matemática, v. 14, n. 1, 2012. 
FURTADO, Ana Luísa Carvalho. Dificuldades na aprendizagem de conceitos abstratos da Álgebra Linear. Dissertação. Universidade Federal do Rio de Janeiro. 2010.

GIAQUINTO, Marcus et al. Visual Thinking in Mathematics. Oxford: Oxford University Press, 2007.

GUZMAN, Miguel de. The Role of Visualization in the Teaching and Learning of Mathematical Analysis, in Proceedings of the International Conference on the Teaching of Mathematics. 2002.

HALBERSTADT, Fabrício Fernando; DE ASSUMPÇÃO, Paula Gabrieli Santos; MATHIAS, Carmen Vieira. Possibilidades de uso do Geogebra no Ensino e Aprendizagem da Geometria: Algumas Reflexões. Educação \& Tecnologia, [S.1.], v. 21, n. 3, ago. 2018. Disponível em: https://periodicos.cefetmg.br/index.php/revista-et/article/view/760. Acesso em: 02 nov. 2019.

KRIPKA, Rosana Maria Luvezute . Uso de tecnologias digitais no ensino e na aprendizagem de álgebra linear na perspectiva das teorias da aprendizagem significativa e dos registros de representação semiótica. Tese de Doutorado. Programa de Pós-Graduação em Educação em Ciências e Matemática.Pontifícia Universidade Católica, Porto Alegre.2018. 593p.

MARMOLEJO-AVENIA, Gustavo Adolfo; GUZMÁN, Lucy Yudy; INSUATY, Ana Lucia. Introducción a las fracciones en textos escolares de educación básica: ¿figuras representaciones estáticas o dinámicas? Revista científica, v. 3, n. 23, p. 43-56, 2015.

OLIVEIRA, Marluce Trentin; LEIVAS, José Carlos Pinto. Visualização e Representação Geométrica com suporte na Teoria de Van Hiele. Ciência e Natura, v. 39, n. 1, p. 108-117, 2017.

PARMEGIANI, Roselice. Explorando as Transformações Lineares no Plano com o Uso do Matlab. Anais do XXXIX COBENGE: Congresso Brasileiro de Educação em Engenharia. 2011

PRESMEG, Norma C. Visualisation and mathematical giftedness. Educational Studies in Mathematics, v. 17, n. 3, p. 297-311, 1986.

PRESMEG, Norma. Contemplating visualization as an epistemological learning tool in mathematics. ZDM, v. 46, n. 1, p. 151-157, 2014.

ROSA, Odileia. et al. Explorando as transformações lineares no plano, através do software WINPLOT. Revista TECCEN, v. 2, n. 2. 2009.

SILVA, A. M. da.; ALVES, A. F.; ALMEIDA, V. R. Um olhar sobre os processos de ensino e aprendizagem da disciplina Álgebra Linear. In: BIANCHINI, B. e MACHADO, S. D. A. (org.) Álgebra Linear sob o ponto de vista da Educação Matemática. São Paulo Editora Livraria da Física, 2018. pp/92-102. 
STERLING, Stephen. Transformative learning and sustainability: Sketching the conceptual ground. Learning and Teaching in Higher Education, v. 5, n. 11, p. 17-33, 2011.

STEWART, Sepideh; LARSON, Christine Andrews; ZANDIEH Michelle. Linear algebra teaching and learning: themes from recent research and evolving research priorities. ZDM: Mathematics Education, v.51, n 7. p. 1017-1030, 2019.

Recebido em dezembro de 2019.

Aprovado em maio de 2020. 